\title{
Thyroglossal Duct Cyst Carcinoma- A Case Report
}

\author{
${ }^{1}$ Ashim Kumar Biswas , ${ }^{1}$ Kazi Shameemus Salam, ${ }^{1}$ Md. Mosleh Uddin , ${ }^{1}$ Kanu Lal Saha , ${ }^{2}$ Belayat Hossain \\ Siddiquee,${ }^{3}$ Mohammad Asraful Islam \\ ${ }^{1}$ Assistant Professor, ${ }^{2}$ Professor, ${ }^{3}$ Medical Officer, Department of Otolaryngology - Head \& Neck Surgery, BSMMU, Dhaka.
}

\begin{abstract}
:
Thyroglossal duct cyst carcinoma in a rare condition. Only around 250 cases of malignant thyroglossal cyst have been reported as far. We report a 45 years old women presenting with a painless swelling in the midline in the upper part of front of neck for $1 \mathrm{yr}$. This swelling moves with deglutition, multilobulated moves up on protrusion of tongue. FNAC revealed cystic lesion compatible with thyroglossal duct cyst. Ultrasonogram revealed mass is separated from thyroid gland. Patient underwent sistrunk's operation and tissue was sent for histopathological examination and report reveled papillary carcinoma of thyroglossal duct cyst.
\end{abstract}

Key words: Thyroglossal cyst, papillary carcinoma, sistrunk's operation.

[BSMMU J $2013 ; 6(2): 172-174]$

\section{Introduction :}

Thyroglossal duct cysts are the most common anomaly in thyroid development. They account for approximately $70 \%$ of congenital neck abnormalities. ${ }^{1}$ In general, duct cysts are benign but $1 \%$ of cases can be malignant. A review of the literature showed that 250 cases of malignant thyroglossal cysts have been reported. The percentage of different types of neoplasm in reported cases of thyroglossal duct cyst are: papillary carcinoma $81.7 \%$, mixed carcinoma $6.9 \%$, squamous cell carcinoma $5.2 \%$, follicular and adenocarcinoma $1.7 \%$ each. ${ }^{3}$ Most case of thyroglossal duct cyst are diagnosed during $3^{\text {rd }} \& 4^{\text {th }}$ decade of life. ${ }^{3}$ In this report, we present a 45 yrs female with a papillary carcinoma of thyroglossal duct cyst, because of its rarity and unusual presentation.

\section{Case presentation :}

A 45 years old women admitted in Head Neck Surgery Division of Bangabandhu Sheikh Mujib Medical University, presenting with a painless swelling in the midline of

Address for Correspondence: Dr. Ashim Kumar Biswas, Assistant Professor Dept of otolaryngology- Head and Neck Surgery, BSMMU, Dhaka Mobile: 01918-127193 the upper part of the front of the neck for 1 year. This swelling moves with deglutition. Swelling was multilobulated and soft around the hyoid bone. Swelling moves up on protrusion of the tongue. Regional lymph node were not enlarged. Thyroid gland was not palpable, FNAC from the swelling revealed cystic lesion compatible with thyroglossal duct cyst. USG of neck revealed mass found in submental region above thyroid cartilage is about $5.9 \times 1.9 \mathrm{~cm}$, cystic in nature with interned septation and a few calcification. The mass is separated from thyroid gland. Thyroid function tests were within normal limits. Patients underwent Sistrunk's operation. There was local sign of capsular invasion and adhesion with surrounding structure. Tissue was sent for histopathological examination. Histopathological report revealed papillary carcinoma of thyroglossal duct. Considering the extra capsular spread of the tumour to facilitate radioiodine ablation whole thyroid was removed preserving all the 4 parathyroid glands and both recurrent laryngeal nerves.

\section{Discussion :}

Thyroglossal cysts are common abnormalities of thyroid development. These cysts originate from epithelial remnants of a persisting thyroglossal duct. Thyroglossal cysts occur more frequently in younger patients. Paillary 
carcinoma arising in a thyroglossal duct cyst is seen most frequently in young women with a sex ratio of $1.5: 1 .^{1}$ These can be located anywhere along the course of the thyroglossal duct, about $75 \%$ are located below the level of hyoid bone. ${ }^{1}$

Benign thyroglossal duct cysts usually present as asymptomatic, soft firm, or hard masses in the midline of the anterior neck and are non tender and generally movable. Malignant thyroglossal duct cysts present in the same manner. Carcinoma should be suspected in any thyroglossal duct cyst that is hard, fixed and irregular or which has undergone recent change. ${ }^{2}$

The first case of carcinoma in a thyroglossal duct cyst was reported by Uchermannin $1917 .{ }^{\prime}$ More than 200 cases of thyroglossal duct carcinomas have been reported in which papillary carcinoma account for $80 \%$ of cases. ${ }^{2}$

The diagnosis of these carcinoma usually made during surgery or from definitive pathological samples. Because the frequency of cancer, thyroglossal duct cyst is very low, the clinician often does not consider an oncologic diagnosis and does not perform a preoperative FNAC. It is recommended that at least 3 puncture or core biopsy shoud be performed to obtain a sample from the cyst wall, this will lead to a correct diagnosis. ${ }^{4}$

When a thyroglossal duct cyst have been excised by Sistrunk's operation and the definitive histological analysis reports malignancy, the thyroid gland must be studied with radiological and scientigraphic examination. ${ }^{2}$

In our case, ultrasonogram of thyroid gland was done and report reveals a mass in supra hyoid region above thyroid cartilage is about $5.9 \times 1.9 \mathrm{~cm}$, cystic in nature with interned septation and a few calcification. The mass was separated from thyroid gland. Thyroid function test was within normal limit. No regional lymph node was found. Regional lymph node metastasis of thyroglossal duct cyst carcinoma occur only $7.7 \%$ of reported cases. ${ }^{4}$ Considering the extra capsular spread of the tumour to facilitate radioiodine ablation whole thyroid was removed preserving all the 4 parathyroid gland and both recurrent laryngeal nerve. There is still controversy about the removal of thyroid gland in the case of papillary carcinoma of thyroglossal duct cyst. ${ }^{4}$ After total thyroidectomy whole body scan was done and suppressive dose of thyroxine was given.

The common surgical procedure used for a thyroglossal duct cyst is Sistrunk's procedure, consisting of excision of the thyroglossal duct cyst, the central portion of the body of the hyoid bone, and a core of tissue around the thyroglossal tract with central core of tongue muscle. In case of malignancy, of total thyroidectomy should be done. Radio-iodine ablation and thyroid suppression should be give in thyroid carcinoma. ${ }^{2}$

Thyroglossal cyst carcinoma is rare and diagnosis is usually made incidentally during histopathological examination of excised cyst. So after Sistrunk's operation, tissue sent for histopathological examination.

The prognosis for papillary thyroglossal duct cyst carcinoma is excellent, with occurrence of metastatic lesion is less than $2 \%$ of cases. ${ }^{1}$

\section{Conclusion :}

Thyroglossal duct cyst carcinoma is very rare. This condition is rarely diagnosed pre-operatively. Once diagnosed, therapy includes total thyroid surgery, adio-active iodine therapy and thyroid suppression.

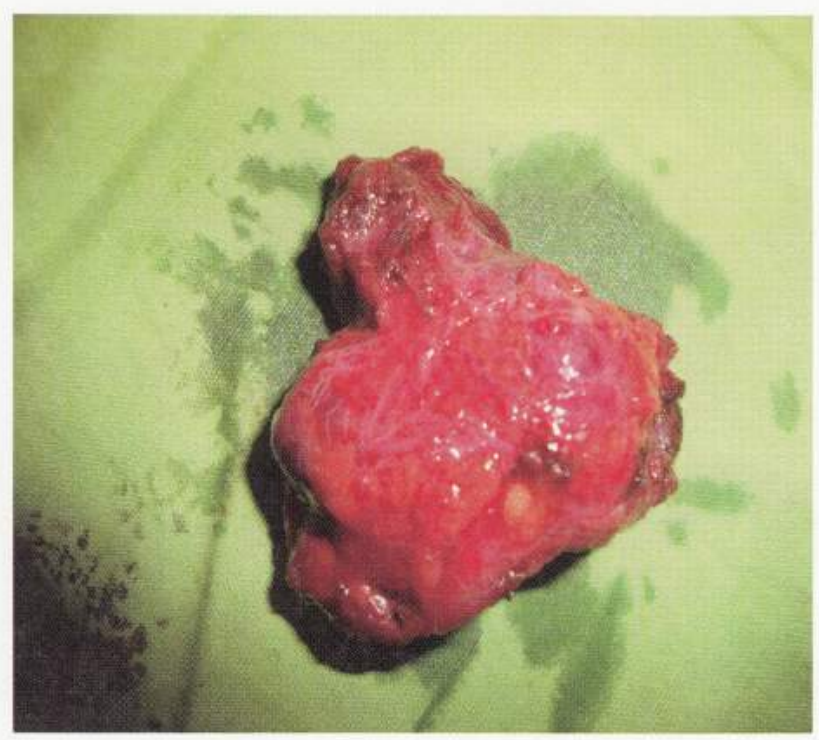

Fig-1: Photographs showing operative removal of thyroglossal duct cyst 


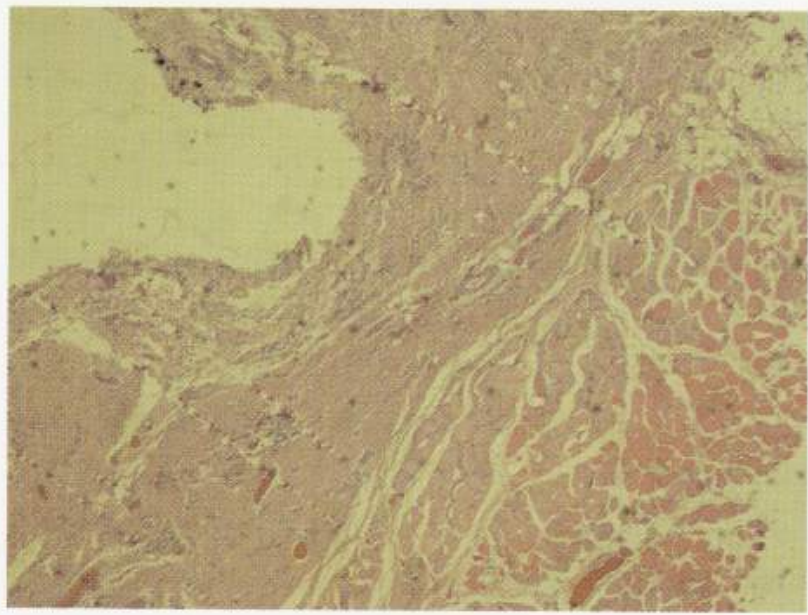

Fig-2: Cyst wall and tumour

\section{References:}

1. Taori K, Rohatgi S, Mahore DM, Dubey J, Saini T, 'Papillary carcinoma in a thyroglossal duct cyst', Ind J of Radiol Imaging, 2005;15(4):531-533.

2. Kandogan T, Erkan N, Vardar E, 'Papillary carcinoma arising in a thyroglossal duct cyst with associated microcarcinoma of the thyroid and without cervical lymph node metastasis: a case report',

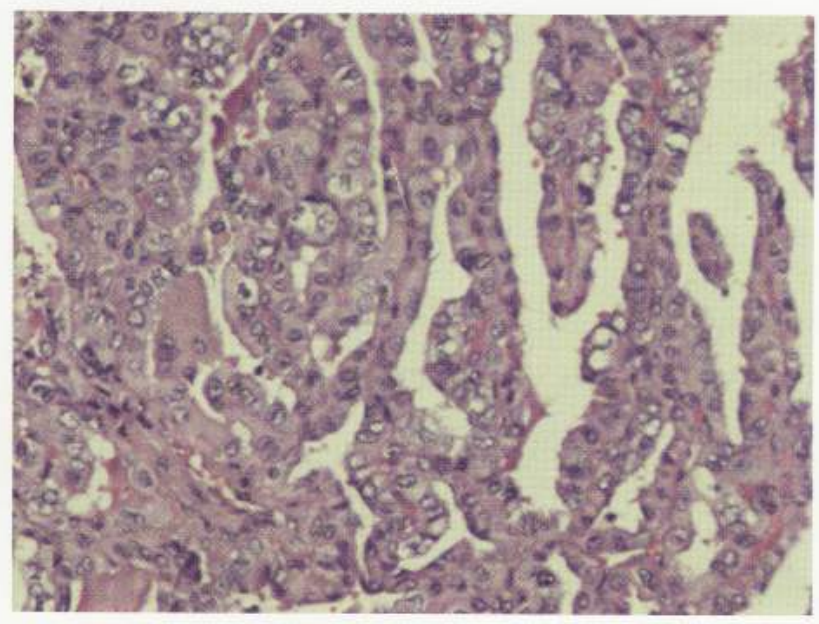

Fig-3: Showing focus of papillary projection

J Med Case Reports, 2008;2:42.

3. Aghaghazvini L, Mazaher H, Sharifian H, Aghaghazvini S, Assadi $\mathrm{M}$, 'Invasive thyroglossal duct cyst papillary carcinoma: a case report', Journal of Medical Case Reports, 2009;3:9308.

4. Thyroglossal Duct Cyst \& Papillary Carcinoma: What Must be done?: Discussion, available at: http://www.medscape.com/viewarticle/ 481349_4. 